\title{
Novel Ferrocenyl Chalcone Derivatives as Antibacterial Agents: Is There a Solution to the Problem?
}

Elecia Jaime Henry ( $\nabla$ elecia.henry@sta.uwi.edu )

University of the West Indies Saint Augustine Campus: The University of the West Indies at St Augustine https://orcid.org/0000-0002-9359-6231

Charles Thomas Bennet

Royal Stoke University Hospital

Michael Collins

Chesterfield Royal Hospital: Chesterfield Royal Hospital NHS Foundation Trust

John Cassella

Staffordshire University

\section{Research Article}

Keywords: Antimicrobial agents, solubilisation, ferrocenyl chalcones, storage conditions, antimicrobial activity

Posted Date: March 17th, 2021

DOI: https://doi.org/10.21203/rs.3.rs-303166/v1

License: (1) This work is licensed under a Creative Commons Attribution 4.0 International License. Read Full License 


\section{Abstract}

Increased infection spread is partly facilitated by reduced new drug development. Because of their antimicrobial properties, ferrocenyl chalcone derivatives were assessed in a previous study. However, dilutions of stock ferrocenyl chalcone solution with Mueller-Hinton broth (MHB) resulted in particle formation, and a colour change from deep red to dark-brown. Results of the current study confirmed particle formation, which suggested the chelation of casein hydrolysate, a component of MHB, by iron ion. After solubilisation in dimethyl sulfoxide (DMSO), each of the iodine-containing compounds, also changed from deep red to dark-brown. Mean rates of colour change (RA) in polypropylene tubes at $37^{\circ} \mathrm{C}$ were the highest $(0.0102 \pm 0.0005 \Delta \mathrm{A} / \mathrm{min}-0.0041 \pm 0.0009 \Delta \mathrm{A} / \mathrm{min})$ while the same observed reaction in borosilicate glass tubes $21^{\circ} \mathrm{C} \pm 1$ were the lowest $(0.0024 \pm 0.0007 \Delta \mathrm{A} / \mathrm{min}-0.0021 \pm 0.0003$ $\Delta \mathrm{A} / \mathrm{min}$ ). Antimicrobial activity of two randomly selected ferrocenyl chalcone compounds (hexyl and heptyl) was unaffected after colour change occurred $(0.016 \mathrm{mg} / \mathrm{ml}-0.125 \mathrm{mg} / \mathrm{ml})$. Although these findings potentially indicate that short-term storage of antimicrobials is unaffected, further work is required to assess whether antimicrobial activity is affected by longer storage conditions.

\section{Introduction}

Due to the increasing global concern of infections caused by drug-resistant bacteria, there is a growing demand for the detection and production of new and effective antibacterial compounds. Research into new sources of potential antibiotics has vastly increased in the pursuit of a positive outcome. One compound that is being explored by researchers are chalcones. Chalcones are plant-based flavonoids that can be found widely in most plant material, including leaves and stems. These chemicals, which influence flower colour and the protection of plants against damaging ultraviolet rays from the sun, have been noted as biologically active with benefits such as anticancer, antiparasitic, antifungal and antibacterial. Because synthetic chalcone compounds can be easily modified, several active derivatives of the organic scaffold have been produced. For example, Liu et al have developed several useful chalcone derivatives with antibacterial activity against $S$. aureus [1].

Although the exact mode of action of chalcones remain uncertain, the consensus regarding the nature of chalcone activity on cells is that the hydrophobic compounds disrupt cell membrane stability resulting in morphological damage and cell death [2, 3]. Sivakumar et al. reported that synthetic chalcone compounds exhibited bactericidal activity against $S$. aureus [3].

Chalcone chemicals, which have been modified with ferrocenyl groups, have been assessed as antimicrobial agents [14]-[18]. These altered compounds possess useful characteristics including small size, increased lipophilicity for diffusing across lipid membranes, and ease of chemical modification [4].

Ferrocenyl chalcone compounds are primarily classified into Type I or Type II (Fig. 1), where the carbonyl group could be located near the ferrocenyl ring in Type I compounds and where the carbonyl group can be found near the phenyl ring in Type II $[4,10]$. 
One possible mechanism of action of ferrocenyl chalcones is to obstruct respiratory enzymes found in the electron transport chain, which is located on the bacterial cell membrane $[4,10]$. Inhibition of bacterial respiration may cause morphological damage to the cell membrane followed by apoptosis.

Clinical diagnoses, prognoses and treatment of diseases with the use of appropriate drugs are determined by assays involving human body fluids such as serum, plasma and cerebro-spinal fluid. Successful activity of antimicrobial agents depends on the solubility of an agent in body fluids, which is a key feature of the bioavailability of the active ingredient in antibiotic drugs. The main routes of antibiotic drug absorption, which ensure maximum system circulation of the active ingredient within the body, are intravenous and oral [11]. Oral administration of drugs is preferred because of the availability of less expensive, but more effective, antibacterial compounds, which can be taken by the outpatients [12]. Systemic distribution of antibiotics within the body via either route usually requires that most drugs be water-soluble [13]. However, since orally administrated antibiotics are absorbed through the intestinal mucosa, these agents must be hydrophobic [22].

Within the last fifteen to twenty years, newly developed antibacterial drugs have gained the interest of researchers because they are water-insoluble and passively diffuse across the lipid bi-layer of cell membranes. Unlike hydrophilic therapeutic molecules, such as $\beta$-lactam drugs, which easily diffuse into cells through membrane-bound porins, hydrophobic drugs diffuse into bacterial cells across the outer membranes of Gram-negative bacteria, which performs the role of additional protection [15]. For example, lipophilic antibacterial drugs are needed for the treatment of bacterial prostatitis, which is enveloped in a hydrophobic membrane [16], and infections of the central nervous system, which is protected by the blood-brain barrier [17]. Due to increased prevalence of infections caused by MDR bacteria, some of which are Gram-negative, there is the need for effective hydrophobic antibiotics. Therefore, the ferrocenyl chalcone compounds used in the current study were engineered to be lipophilic chemicals. These chemicals are synthetic derivatives of flavonoids, on which lipophilic data, defined by the octanol-water partition coefficient [18], is variable.

Novel substituted ferrocenyl chalcone compounds used in the Henry et al. study [10]

Ten ferrocenyl chalcone derivatives (Fig. 2), which were provided by Crouch [19], were assessed as novel antimicrobial agents and were highly hydrophobic compounds due to the addition of increasing lengths of alkyl chains, the addition of ferrocene groups, and the substitution of $\mathrm{C} 5$ on the benzene rings with nitrogen atom [10].

These compounds were designated methyl to decyl based on the number of carbons found in each alkyl group. Five of these ferrocenyl chalcone chemicals used in the Henry et al. study, i.e., pentyl, hexyl, heptyl, octyl, nonyl and decyl, exhibited antibacterial activity from $0.008 \mathrm{mg} / \mathrm{ml}$ to $0.125 \mathrm{mg} / \mathrm{ml}$ against Grampositive lab-adapted organisms and resistant and non-resistant Gram-positive clinical isolates [10]. The alkyl groups of saturated, unbranched alkanes are water-insoluble and their hydrophobicity increases as chain length increases, as described by Stoker [20]. The second group, ferrocene, an aromatic metallocene, is also insoluble in water. The third component of the ferrocenyl chalcone compounds used 
in the current study, a nitrogen substituted benzene ring, is a highly water-insoluble aromatic cyclic structure.

Observations from the Henry et al. study raised aspects of solubility and the hydrophobicity of the ferrocenyl chalcone compounds necessitated the use of an appropriate solvent to enable the preparation of stock solutions for further dilution in an aqueous broth for antimicrobial sensitivity testing. In the same study, DMSO, absolute ethanol, polyethylene glycol and ( \pm )-6-Hydroxy-2,5,7,8-tetramethylchromane-2carboxylic acid (trolox) were used. Despite completely dissolving the ferrocenyl chalcone compounds, one observation was that the stock solutions exhibited precipitation when diluted with bacterial growth solutions. DMSO was the most favourable compound of choice since it is amphipathic and is less inhibitive in terms of bacterial cell growth [21] when compared to the other assessed compounds.

All of the compounds investigated were found to be completely soluble in $100 \%$ DMSO. However, an issue observed in the study was that the solutions altered colour from deep red to dark brown within 2 hours. Additionally, at $2 X$ and $4 X$ dilutions in Mueller Hinton Broth (MHB), fine brown particles were also seen when the solutions were diluted with MHB, which contains dehydrated infusion from beef, casein hydrolysate and starch, as detailed by Oxoid [22]. However, the brown particles were observed after incubation. Nitin [23] have reported that particle size in suspensions are $0.4 \mu \mathrm{m}$ to $12 \mu \mathrm{m}$, and are visible to the naked eye. MHB is the preferred medium since the broth efficiently supports the growth of most aerobic non-fastidious bacteria and extensive research information has been gathered from assays involving the medium [24]. This broth is the reference medium for AST [25].

\section{Colour change of ferrocenyl chalcone compounds}

Once dissolved in DMSO, the stock ferrocenyl chalcone solutions were observed to change from deep red to dark brown in polypropylene tubes at a faster rate than in borosilicate glass tubes. Assuming that the colour change in the Henry et al. study [10] was due to displaced iodine, diethyl ether was added to the solutions containing colour change. Hildebrand et al. [26] were the first to report the use of diethyl ether to demonstrate the possible presence of displaced iodine, where a top layer comprised of a brown ring of iodine suspension and a clear, colourless bottom layer were observed. This solvent was used since solid iodine readily dissolves in polar solvents such as diethyl ether.

The objective of the current study was to assess the issues related to the colour change of the most effective ferrocenyl chalcone compounds including the observation of the dark-brown particles seen after solubilisation, the possible identification of the precipitate, the influence of environmental conditions on colour change and antibacterial activity.

\section{Results And Discussion}

In the current study, the effect of specific environmental conditions on the compounds, as well as the consequent antimicrobial activity of the altered compounds, were assessed. This project was influenced by observations from the antimicrobial sensitivity tests that were performed by Henry et al. [10] where the 
dissolved ferrocenyl chalcones changed from reddish-brown to dark brown after incubation at room temperature (approximately $21^{\circ} \mathrm{C}$ ) and $37^{\circ} \mathrm{C}$ in 96-well polystyrene plates and disposable $13 \mathrm{ml}$ Sarstedt polypropylene tubes. This occurred during preparation of stock solution and working solutions for the determination of MIC of the compounds against a selected panel of bacteria. It was also observed that when the compounds were dissolved and diluted in borosilicate glass tubes, followed by incubation at $37^{\circ} \mathrm{C}$, visible colour change appeared to happen at a slower rate. The visible change in colour of the compounds, which were possible indications of instability after dissolution and whether this potential issue resulted in structural changes and, further to that, affected antimicrobial activity, warranted further investigation.

Due to the absence of literature on the colour change of ferrocenyl chalcone compounds in solution, the possible conditions that influenced the visible colour change of the ferrocenyl chalcone compounds with longer chains (hexyl to decyl) were assessed. The current research involved incubation of the compounds, dissolved in appropriate volumes of DMSO, under the following conditions: room temperature $\left(21^{\circ} \mathrm{C} \pm 1^{\circ} \mathrm{C}\right)$ and light, room temperature $\left(21^{\circ} \mathrm{C} \pm 1^{\circ} \mathrm{C}\right)$ and darkness, and $37^{\circ} \mathrm{C}$ in an incubator. Another aim of study was to assess whether antibacterial activity of the compounds against Gram-positive and Gram-negative bacteria were affected post-incubation under the aforementioned conditions. Based on initial observations regarding the occurrence of colour change in DMSO, it was proposed that change in absorbance, indicative of visible colour change, would occur at a faster rate in polypropylene tubes than in borosilicate glass tubes across all the environmental conditions. These observations also led to proposition that the antibacterial activity of the solubilised compounds would be the same, regardless of the type of tube used.

\section{Observed precipitate in a selected ferrocenyl chalcone (nonyl)}

Solutions in all tubes (tubes 1-6), except control (tube 7), changed colour from deep red to dark brown in the presence of DMSO. Solutions in tubes 1 and 2 with water as the diluent (Figures 3.1 \& 3.2) exhibited no fine brown particles, while solutions in tubes 3 and 4 with MHB diluent exhibited fine brown particles (Figures $3.3 \& 3.4$ ) regardless of sonication. Tubes 5 and 6 (Figures $3.5 \& 3.6$ ) were shown to demonstrate the lack of formation of fine brown precipitate when MHB is not added while tube 7 (not shown) exhibited no particle formation.

One possible explanation for the appearance of these brown particles, visible to the naked eye, may be the chelation of $\mathrm{Fe}^{2+}$ ions, present in the ferrocene group, by hydrolysate in MHB [27]. Luo et al. observed that hydrolysis of proteins, such as sodium caseinate, produces casein hydrolysate, a component of $\mathrm{MHB}$, and enhances the metal ion chelating activity of the protein hydrolysate. Gu et al. (2010) reported that Maillard Reaction Products (MRP), which contain casein hydrolysate, exhibited $\mathrm{Fe}^{2+}$ chelation. This reaction was also reported by Luo et al. [27], where the group assessed the $\mathrm{Fe}^{2+}$ chelation activity of casein hydrolysates. The IUPAC [29] defines chelation as "the formation or presence of bonds (or other attractive interactions) between two or more separate binding sites within the same ligand and a single central atom". It has been reported that $\mathrm{Fe}^{2+}$ chelation activity of hydrolysates can result in hydrophobic 
protein-metal complexes [30], which potentially caused the appearance of macroscopic particles. Therefore, a possible theory on the presence of observed fine brown particles in the current method may be the formation of casein hydrolysate-iron complexes caused by the chelation of iron ions in MHBdiluted ferrocenyl chalcone solution. When observed by Henry et al. [10], these complexes were reversible since increased dilution with MHB led to reduced appearance of particles.

\section{Assay for displaced iodine}

Diethyl ether, an organic solvent that completely solubilises iodine to form a stable solution, would dissolve a precipitate if it is iodine. The reaction between the ferrocenyl chalcone and diethyl ether produced a brown precipitate at the bottom of the tube instead of a brown ring at the top of the solution (not pictured). Since a brown precipitate was seen, the change in colour of the ferrocenyl chalcone was not caused by displaced iodine but may be the presence of an equal mix of ferrocene (deep red) and ferrocenium (deep blue), which creates the brown colour. Although ferrocene is predicted to be soluble in most organic solvents [31], Herrmann [32] has indicated that ferrocene is sparingly soluble in diethyl ether.

\section{Influence of conditions on colour change of hexyl to decyl ferrocenyl chalcones}

After solubilisation in DMSO in polypropylene tubes, the hexyl to decyl ferrocenyl chalcones changed from deep red to dark brown (Figure 4). This was also seen in borosilicate tubes (not shown).

The results of the current study (Table 1 ) indicated that at room temperature and in light, the mean ( \pm SD) rates of change in absorbance were $0.0097 \pm 0.0007 \Delta \mathrm{A} / \mathrm{min}$ (hexyl), $0.0095 \pm 0.0007 \Delta \mathrm{A} / \mathrm{min}$ (nonyl) and $0.0091 \pm 0.0012 \Delta \mathrm{A} / \mathrm{min}$ (decyl) in polypropylene tubes. They also showed that the mean $( \pm \mathrm{SD})$ rates of change in borosilicate glass tubes were $0.0056 \pm 0.0022 \Delta \mathrm{A} / \mathrm{min}$ (hexyl), $0.0053 \pm 0.0017$ $\Delta \mathrm{A} / \mathrm{min}$ (nonyl) and $0.0056 \pm 0.0017 \Delta \mathrm{A} / \mathrm{min}$ (decyl). These estimated values were significantly different between polypropylene tubes and borosilicate tubes where $\mathrm{p}=0.0015$ (hexyl), $\mathrm{p}=0.0001$ (nonyl) and 0.0021 (decyl). In the same study, it was found that there were no significant differences in the mean $( \pm$ SD) rates of change in polypropylene and borosilicate glass tubes produced by heptyl $(p=0.1894)$ and nonyl $(p=0.1049)$.

Further findings from the study (Table 1 ) indicated that, after exposure to $37^{\circ} \mathrm{C}$, the rates of change in absorbance of all five ferrocenyl chalcone compounds were significantly different between polypropylene tubes and borosilicate glass tubes where $p=0.0112$ (hexyl), $p=0.0100$ (heptyl), $p=0.0123$ (octyl), $p=0.0017$ (nonyl) and $p=0.0129$ (decyl). The rates of change in the polypropylene tubes were $0.0102 \pm 0.0005$ $\Delta \mathrm{A} / \mathrm{min}$ for hexyl, $0.0096 \pm 0.007 \Delta \mathrm{A} / \mathrm{min}$ for heptyl, $0.0092 \pm 0.009 \Delta \mathrm{A} / \mathrm{min}$ for octyl, $0.0096 \pm 0.0007$ $\Delta \mathrm{A} / \mathrm{min}$ for nonyl and $0.0088 \pm 0.0007 \Delta \mathrm{A} / \mathrm{min}$ for decyl. In borosilicate glass tubes, the rates of change were lower for hexyl $(0.0078 \pm 0.0018 \Delta \mathrm{A} / \mathrm{min})$, heptyl $(0.0076 \pm 0.0032 \Delta \mathrm{A} / \mathrm{min})$, octyl $(0.0060 \pm 0.0024$ $\Delta \mathrm{A} / \mathrm{min})$, nonyl $(0.0058 \pm 0.0020 \Delta \mathrm{A} / \mathrm{min})$ and decyl $(0.0059 \pm 00.0022 \Delta \mathrm{A} / \mathrm{min})$. This indicated that higher temperatures affected colour stability of the ferrocenyl chalcone compounds. 
In the current study, the exposure of all 5 ferrocenyl chalcone compounds to room temperature and darkness resulted in significant differences between the rates of change in absorbance in polypropylene tubes and borosilicate glass tubes where $\mathrm{p}=0.0042$ (hexyl), $\mathrm{p}=0.0006$ (heptyl), $\mathrm{p}=0.0006$ (octyl), $\mathrm{p}=0.0008$ (nonyl), and $p=0.0067$ (decyl). The rates of absorbance change in the polypropylene tubes were $0.0051 \pm$ $0.0080 \Delta \mathrm{A} / \mathrm{min}$ for hexyl, $0.0045 \pm 0.0010 \Delta \mathrm{A} / \mathrm{min}$ for heptyl, $0.0044 \pm 0.0008 \Delta \mathrm{A} / \mathrm{min}$ for octyl, $0.0042 \pm$ $0.0007 \Delta \mathrm{A} / \mathrm{min}$ for nonyl and $0.0041 \pm 0.0009 \Delta \mathrm{A} / \mathrm{min}$ for decyl. In the borosilicate glass tubes, the rates of absorbance change were $0.0024 \pm 0.0007 \Delta \mathrm{A} / \mathrm{min}$ for hexyl, $0.0023 \pm 0.0005 \Delta \mathrm{A} / \mathrm{min}$ for heptyl, $0.0021 \pm 0.003 \Delta \mathrm{A} / \mathrm{min}$ for octyl, $0.0024 \pm 0.0006 \Delta \mathrm{A} / \mathrm{min}$ for nonyl and $0.0023 \pm 0.0008 \Delta \mathrm{A} / \mathrm{min}$ for decyl. Although absorbance change occurred under dark conditions, the rates of change were lower than those that were observed under light conditions. Another finding of the study was that the effect of the selected environmental conditions was significantly different. With respect to the five ferrocenyl chalcone solutions in polypropylene tubes, there were significant differences in the rates of change in absorbance between the environmental conditions, where $p=0.00002$ (hexyl), $p=0.00005$ (heptyl), $p=0.000006$ (octyl), $p=0.0000007$ (nonyl) and $p=0.000003$ (decyl). There were significant differences in the rates of change in absorbance also for the same solutions in borosilicate glass tubes, between the environmental conditions, where $\mathrm{p}=0.0005$ (hexyl), $\mathrm{p}=0.0032$ (heptyl), $\mathrm{p}=0.0039$ (octyl), $\mathrm{p}=0.0076$ (nonyl) and $\mathrm{p}=0.0069$ (decyl).

Based on the results presented, it can be suggested that visible colour change of the ferrocenyl chalcone solutions was possibly influenced by the composition of the sample vessels, where samples were prepared in polypropylene and borosilicate glass tubes, and that light and heat accelerated this change. The change in the observed colour of the ferrocenyl chalcone solutions may have resulted from the oxidation of $\mathrm{Fe}^{2+}$, found in the ferrocene group, to $\mathrm{Fe}^{3+}$, found in the ferrocenium group [33]. This may indicate a reaction between the solution and potential pro-oxidant components in polypropylene tubes [34]. However, iron oxidation in aqueous ferrocene, which is reddish brown in colour, produces aqueous ferrocenium, which is blue in colour. Thus, this oxidation may be reversible and may result in the presence of both ferrocene and ferrocenium [35], producing a dark brown colour. This is the first known report that specifically addresses the change in colour of ferrocenyl chalcone compounds in relation to the sample vessel and environmental conditions to which the compounds are exposed. Therefore, there is a need for further investigation of this theory, including the identification of the presence of ferrocenium.

\section{Antibacterial activity of the ferrocenyl chalcone compounds after exposure to environmental conditions}

The findings of the next phase of assay (Table 2) indicated that heptyl ferrocenyl chalcone compound possessed more efficacy in overall antibacterial activity than hexyl ferrocenyl chalcone compound. In the study, heptyl produced the largest overall MIC value of $0.500 \mathrm{mg} / \mathrm{ml}$ against E. coli NCIMB 9483 . The MIC values estimated against Gram-negative bacteria in the study $(0.250 \mathrm{mg} / \mathrm{ml}$ to $0.500 \mathrm{mg} / \mathrm{ml})$ were not considered to reflect antibacterial activity, since the percentage of DMSO that was present in the solution were greater than $12.5 \% \mathrm{v} / \mathrm{v}$ DMSO. DMSO has been reported to exhibit antibacterial activity at concentrations $\geq 12.5 \% \mathrm{v} / \mathrm{v}[36]$ It was also discovered that hexyl produced the same MIC values in both 
polypropylene tubes and borosilicate glass tube with $0.063 \mathrm{mg} / \mathrm{ml}$ against $S$. aureus NCIMB 8244 and $0.125 \mathrm{mg} / \mathrm{ml}$ against $E$. faecalis NCTC 12697 . The heptyl ferrocenyl chalcone compound produced different MIC values in polypropylene tubes when compared to assays in borosilicate glass tubes. The MIC values were estimated to be $0.016 \mathrm{mg} / \mathrm{ml}$ against $S$. aureus NCIMB 8244 and $0.031 \mathrm{mg} / \mathrm{ml}$ against E. faecalis NCTC 12697 in polypropylene tubes, and $0.031 \mathrm{mg} / \mathrm{ml}$ against $S$. aureus NCIMB 8244 and $0.063 \mathrm{mg} / \mathrm{ml}$ against $E$. faecalis NCTC 12697 in borosilicate glass tubes.

At these MIC values, antibacterial activity was possibly caused by the presence of ferrocenyl chalcone, since DMSO displays antibacterial activity at $\geq 12.5 \%$ [36]. The antibacterial activity of DMSO was explored further by Henry et al. [10]. When the same four organisms were exposed to DMSO, followed by serial dilution 2-fold with MHB, in both polypropylene and borosilicate glass tubes, this resulted in MIC values from $12.5 \% \mathrm{v} / \mathrm{v}$ DMSO to $25 \% \mathrm{v} / \mathrm{v}$ DMSO. Overall, the results indicated that antibacterial activity of the ferrocenyl chalcones remained after exposure to environmental conditions.

\section{Conclusion}

The bioavailability of an antimicrobial drug in the human body relies on the solubility of the compound in hydrophilic body fluids. The most effective antimicrobial agents are orally administered antimicrobial compounds, which are absorbed in the intestine. Orally administered antimicrobial drugs must be hydrophobic so that they may enter the mucosa by diffusion. Additionally, hydrophobic antimicrobial drugs are preferred since they diffuse across highly protected tissues such as the blood brain barrier and the prostate. Due to their hydrophobic nature, such drugs must be dissolved in amphipathic compounds, which allow the drug to diffuse across the hydrophobic barriers but still be capable of targeting hydrophilic targets.

The antimicrobial compounds used in this study contained hydrophobic moieties. DMSO, an amphipathic chemical, was determined to be the best solvent for the ferrocenyl chalcone compounds. After solvation in DMSO, the ferrocenyl chalcone solutions were diluted with MHB, the standard medium used in AST. However, initial solvation and dilution resulted in a colour change from deep red to dark brown, and the production of brown particles that were visible to the naked eye.

$\mathrm{Fe}^{2+}$ chelation by casein hydrolysate, a chelating component of $\mathrm{MHB}$, was suggested to be the potential cause of particulate formation in the ferrocenyl chalcones in the current study. The cause of the colour change from deep red to dark brown was hypothesised to be the presence of displaced iodine. However, a negative diethyl ether test, meant that iodine was not displaced after solubilisation. The presence of prooxidant compounds in polyethylene vessels was proposed to be the possible cause of the oxidation of $\mathrm{Fe}^{2+}$ in ferrocene to $\mathrm{Fe}^{3+}$ in ferrocenium. This reversible colour change may have resulted in an equivalent mix of ferrocene (deep red) and ferrocenium (deep blue), which formed the dark brown colour.

An assessment on the effect of environmental conditions of ferrocenyl chalcone compounds and their consequent antimicrobial activity revealed key findings. These findings were that solubilised ferrocenyl 
chalcone compounds should be stored at room temperature in the dark. Another finding was that the antimicrobial activity of the compounds remained, despite exposure to specific environmental conditions, so therefore, this is not an issue affecting the ability of the chalcones to exhibit antibacterial activity. Overall, neither colour change, nor the formation of brown particles, affected the activity of these compounds after solubilisation in DMSO. The finding of sustained antimicrobial activity corresponds with the findings that were reported by Henry et al. [10], especially that of favourable activity against Gram-positive lab-adapted bacteria. Since this is the first known study of its kind with respect to colour change and precipitate formation when ferrocenyl chalcone compounds are dissolved and diluted, further work is needed to confirm the occurrence of $\mathrm{Fe}^{2+}$ oxidation after solubilisation of the ferrocenyl chalcone compounds. The theory that temperature, light and type of reaction vessel influences colour change of these compounds, and that the dilution of solubilised compounds in MHB exhibit the reversible formation of particles may result from iron ion chelation by casein hydrolysate in MHB The findings of the current study could significantly contribute to the development of current and future antimicrobial compounds, which are urgently needed to complement the rapidly dwindling cache of antibiotic therapies, in terms of the importance of medium to long term storage in order to preserve the functionality and efficacy of such compounds against non-resistant and resistant bacteria.

\section{Materials And Methods}

\section{Preparation of a selected ferrocenyl chalcone for observed precipitate}

Fresh stock nonyl ferrocenyl chalcone solutions were prepared by dissolving $1 \mathrm{mg}$ of powder in $1 \mathrm{ml}$ of DMSO in a sterile polypropylene tube (tube 1) and in a sterile borosilicate glass tube (tube 2). Stock MHB and deionised water were autoclaved at $121^{\circ} \mathrm{C}$ for 15 minutes and dispensed into $10 \mathrm{ml}$ aliquots. Test sterile polypropylene tubes $(2 \times 75 \mu$ sterile deionised water and $2 \times 75 \mu \mathrm{MHB})$ were prepared and $75 \mu \mathrm{l}$ of dissolved stock ferrocenyl was added to each tube (tubes $3-6$ ). A control tube (tube 7) containing $150 \mu \mathrm{l}$ MHB was also prepared. One tube with MHB diluent (tube 3) and one tube with water diluent (tube 5) were sonicated for approximately two minutes. All tubes were sealed and observed for colour change and precipitate pre- and post-incubation at $37^{\circ} \mathrm{C}$ for 72 hours. This method was performed in duplicate.

\section{Preparation of sample for displaced iodine assay}

$1 \mathrm{mg}$ of solid decyl ferrocenyl chalcone was dissolved in $1 \mathrm{ml}$ of DMSO in a $1.5 \mathrm{ml}$ Eppendorf microcentrifuge tube made of polypropylene and incubated overnight at room temperature in a cupboard. After observing a colour change from deep red to dark brown in each solution, $0.1 \mathrm{ml}$ of dissolved decyl chalcone was added to an equal volume of diethyl ether in a borosilicate glass tube. The solution was then visually observed for the presence of an upper brown layer.

\section{Influence of environmental conditions on colour change}

$1 \mathrm{mg} / \mathrm{ml}$ stock solutions of hexyl to decyl ferrocenyl chalcone compounds in DMSO were prepared in 5 polypropylene tubes and 5 borosilicate glass tubes per environmental condition. Each tube was prepared 
in triplicate (18 tubes per ferrocenyl chalcone) where 6 tubes were incubated at room temperature $\left(21^{\circ} \mathrm{C} \pm\right.$ $\left.1^{\circ} \mathrm{C}\right)$ and light, another 6 tubes were incubated at room temperature $\left(21^{\circ} \mathrm{C} \pm 1^{\circ} \mathrm{C}\right)$ and the final 6 tubes were incubated in darkness and at $37^{\circ} \mathrm{C}$. Absorbance values were measured at $620 \mathrm{~nm}$ using a WPA Biowave II spectrophotometer (Biochrom Limited, Cambourne, UK) at 30-minute intervals up to 5 hours.

Antibacterial activity of the ferrocenyl chalcone compounds after exposure to environmental conditions

After exposure to environmental conditions, two randomly selected compounds (hexyl and heptyl) were diluted with MHB, produce working concentrations of $1 \mathrm{mg} / \mathrm{ml}$. The positive control was either penicillin$\mathrm{G}$ or oxytetracycline. Each stock antibiotic solution was prepared to $0.256 \mathrm{mg}$ per $1 \mathrm{ml}$ of sterile deionised water. The negative control was $5 \% \mathrm{v} / \mathrm{v}$ DMSO, which was diluted with MHB. Using 2-fold serial macrodilution in both polypropylene and borosilicate glass tubes, the final chalcone concentration of ferrocenyl chalcone ranged from $0.500 \mathrm{mg} / \mathrm{ml}$ to $0.001 \mathrm{mg} / \mathrm{ml}$, and a final antibiotic concentration of $0.128 \mathrm{mg} / \mathrm{ml}$ where samples were done in duplicate.

Two Gram-positive bacteria, Staphylococcus aureus NCIMB 8244 and Enterococcus faecalis NCTC 12697, and two Gram-negative bacteria, Salmonella "Manchester" NCTC 7832 and Escherichia coli NCIMB 9483 were used in this assay. Each inoculum was prepared in sterile MHB to achieve concentrations between $10^{7}$ and $10^{8} \mathrm{cfu} / \mathrm{ml}$. The suspensions were diluted to achieve the final inoculum of $10^{5} \mathrm{cfu} / \mathrm{ml}$. An appropriate volume of each inoculum was added to the relevant tube that contained ferrocenyl chalcone or antibiotic solution. After incubating in air for $18-24$ hours at $37^{\circ} \mathrm{C}$, absorbance values were measured at $620 \mathrm{~nm}$, followed by numeration of viable bacterial colonies using the Miles and Misra method.

\section{Declarations}

Funding sources: This research did not receive any specific grant from funding agencies in the public, commercial, or not-for-profit sectors.

Conflict of interest: none.

Ethical approval: This article does not contain any studies with human participants or animals performed by any of the authors.

\section{References}

[1] Liu XL, Xu YJ, Go ML. Functionalized chalcones with basic functionalities have antibacterial activity against drug sensitive Staphylococcus aureus. Eur J Med Chem 2008;43:1681-7. doi:10.1016/j.ejmech.2007.10.007.

[2] Nielsen SF, Larsen M, Boesen T, Schønning K, Kromann H. Cationic Chalcone Antibiotics . Design , Synthesis, and Mechanism of Action. J Med Chem 2005;48:2667-77. 
[3] Sivakumar PM, Priya S, Doble M. Synthesis, Biological Evaluation, Mechanism of Action and Quantitative Structure - Activity Relationship Studies of Chalcones as Antibacterial Agents. Chem Biol Drug Des 2009;73:403-15. doi:10.1111/j.1747-0285.2009.00793.x.

[4] Attar S, O’Brien Z, Alhaddad H, Golden ML, Calderón-Urrea A. Ferrocenyl chalcones versus organic chalcones: a comparative study of their nematocidal activity. Bioorg Med Chem 2011;19:2055-73. doi:10.1016/j.bmc.2011.01.048.

[5] Pejović A, Damljanović I, Stevanović D, Vukićević M, Novaković SB, Bogdanović G, et al. Antimicrobial ferrocene containing quinolinones: Synthesis, spectral, electrochemical and structural characterization of 2-ferrocenyl-2,3-dihydroquinolin-4(1H)-one and its 6-chloro and 6-bromo derivatives. Polyhedron 2012;31:789-95. doi:10.1016/j.poly.2011.11.006.

[6] Kowalski K, Koceva-Chy A, Szczupak L, Hikisz P, Bernasińska J, Rajnisz A, et al. Ferrocenylvinylflavones: Synthesis, structure, anticancer and antibacterial activity studies. J Organomet Chem 2013;741-742:153-61. doi:10.1016/j.jorganchem.2013.05.009.

[7] Prasath R, Bhavana P, Ng SW, Tiekink ERT. The facile and efficient ultrasound-assisted synthesis of new quinoline-appended ferrocenyl chalcones and their properties. J Organomet Chem 2013;726:62-70. doi:10.1016/j.jorganchem.2012.12.022.

[8] Ahmed N, Konduru NK, Owais M. Design, synthesis and antimicrobial activities of novel ferrocenyl and organic chalcone based sulfones and bis-sulfones. Arab J Chem 2019;12:1879-94. doi:10.1016/j.arabjc.2014.12.008.

[9] Henry EJ, Smith RB, Collins M, Bird SJ, Gowland P, Cassella JP. Novel Ferrocenyl Chalcone Compounds as Possible Antimicrobial Agents. In: Méndez Vilas A, editor. Antimicrob. Res. Nov. Bioknowledge Educ. Programs, Spain: Formatex Research Centre; 2017, p. 140-8.

[10] Henry EJ, Bird SJ, Gowland P, Collins M, Cassella JP. Ferrocenyl chalcone derivatives as possible antimicrobial agents. J Antibiot (Tokyo) 2020;73:299-308 (2020). doi:10.1038/s41429-020-0280-y.

[11] Levison ME, Levison JH. Pharmacokinetics and Pharmacodynamics of Antibacterial Agents. Infect Dis Clin North Am 2009;23:791-819. doi:10.1016/j.idc.2009.06.008.Pharmacokinetics.

[12] Cyriac JM, James E. Switch over from intravenous to oral therapy: A concise overview. J Pharmacol Pharmacother 2014;5:83-8. doi:10.4103/0976-500X.130042.

[13] Gao P, Nie X, Zou M, Shi Y, Cheng G. Recent advances in materials for extended-release antibiotic delivery system. J Antibiot (Tokyo) 2011;64:625-34. doi:10.1038/ja.2011.58.

[14] Goddard AF. Review article: factors influencing antibiotic transfer across the gastric mucosa. Aliment Pharmacol Ther 1998;12:1175-84. 
[15] Delcour AH. Outer Membrane Permeability and Antibiotic Resistance. Biochim Biophys Acta 2009;1794:808-16. doi:10.1016/j.bbapap.2008.11.005.Outer.

[16] Lipsky BA, Byren I, Hoey CT. Treatment of Bacterial Prostatitis. Clin Infect Dis 2010;50:1641-52. doi:10.1086/652861.

[17] Nau R, Sorgel F, Eiffert H. Penetration of Drugs through the Blood-Cerebrospinal Fluid / Blood-Brain Barrier for Treatment of Central Nervous System Infections. Clin Microbiol Rev 2010;23:858-83. doi:10.1128/CMR.00007-10.

[18] Rothwell JA, Day AJ, Morgan MRA. Experimental Determination of Octanol - Water Partition Coefficients of Quercetin and Related Flavonoids. J Agric Food Chem 2005;53:4355-4360.

[19] Crouch LLE. The Synthesis of Organometallic Chalcones. University of Central Lancashire, 2014. [20] Stoker HS. General, Organic and Biological Chemistry. 7th ed. Boston: Cengage Learning; 2015. [21] Hassan AS. The Antibacterial Activity of Dimethyl Sulfoxide (DMSO) with and without of Some Ligand Complexes of the Transitional Metal lons of Ethyl Coumarin against Bacteria Isolate from Burn and Wound Infection. J Nat Sci Res 2014;4:106-11.

[22] Oxoid. CM0405, Mueller-Hinton Broth__ Oxoid - Product Detail. Oxoid Microbiol Prod 2017. http://www.oxoid.com/UK/blue/prod_detail/prod_detail.asp?pr=CM0405 (accessed May 20, 2017).

[23] Nitin K. Longman Science. 1st ed. New Delhi: Dorling Kindersley; 2009.

[24] CLSI. Methods for Dilution Antimicrobial Susceptibility Tests for Bacteria That Grow Aerobically; Approved Standard - Ninth Edition. vol. 32. Pennsylvania: 2012.

[25] EUCAST. EUCAST DISCUSSION DOCUMENT - Determination of minimum inhibitory concentrations (MICs) of antibacterial agents by broth dilution. Munich: 2003.

[26] Hildebrand JH, Benesi HA, Mower LM. Solubility of lodine in Ethyl Alcohol, Ethyl Ether, Mesitylene, pXylene, 2,2-Dimethylbutane, Cyclohexane and Perfluoro-n-heptane. J Am Chem Soc 1950;72:1017-20. doi:10.1021/ja01158a096.

[27] Luo Y, Pan K, Zhong Q. Physical, chemical and biochemical properties of casein hydrolyzed by three proteases: Partial characterizations. Food Chem 2014;155:146-54.

doi:10.1016/j.foodchem.2014.01.048.

[28] Gu F, Kim JM, Abbas S, Zhang X, Xia S, Chen Z. Structure and antioxidant activity of high molecular weight Maillard reaction products from casein - glucose. Food Chem 2010;120:505-11. doi:10.1016/j.foodchem.2009.10.044.

[29] IUPAC. Chelation. Compend Chem Terminol 1997. doi:https://doi.org/10.1351/goldbook.C01012. 
[30] Chinedu C, Min U. Role of surface charge of hydrolysed bovine caseins in their iron ( II ) -binding affinity and antioxidative capacity in iron ( II ) -facilitated $\beta$-carotene and glutathione oxidation. J Food Nutr Res 2017;56:149-54.

[31] Yousefinjad S, Honarasa F, Solhjoo A. On the Solubility of Ferrocene in Nonaqueous Solvents. J Chem Eng Data 2015;10:1-8. doi:10.1021/acs.jced.5b00768.

[32] Herrmann WA. Synthetic Methods of Organometallic and Inorganic Chemistry. 1st ed. New York: Georg Thieme Verlag; 1997.

[33] Charette MA, Sholkovitz ER. Oxidative precipitation of groundwater-derived ferrous iron in the subterranean estuary of a coastal bay. Geophys Res Lett 2002;29:1-4. doi:10.1029/2001GL014512.

[34] Corti A, Muniyasamy S, Vitali M, Imam SH, Chiellini E. Oxidation and biodegradation of polyethylene films containing pro-oxidant additives: Synergistic effects of sunlight exposure, thermal aging and fungal biodegradation. Polym Degrad Stab 2010;95:1106-14. doi:10.1016/j.polymdegradstab.2010.02.018.

[35] Rao MR, Kumar KVP, Ravikanth M. Synthesis of boron-dipyrromethene - ferrocene conjugates. J Organomet Chem 2010;695:863-9. doi:10.1016/j.jorganchem.2010.01.009.

[36] Duric K, Kovac-besovic E, Niksic H, Sofic E. Antibacterial Activity of Methanolic Extracts, Decoction and Isolated Triterpene Products From Different Parts of Birch, Betula pendula, Roth. J Plant Stud 2013;2:61-70. doi:10.5539/jps.v2n2p61.

\section{Tables}

Table 1 - RA ( $\Delta \mathrm{A} / \mathrm{min})$ of each ferrocenyl chalcone based on type of vessel and environmental condition. 


\begin{tabular}{|c|c|c|c|}
\hline Chalcone & Vessel & Condition & $\mathrm{RA}(\Delta \mathrm{U} / \mathrm{min})$ \\
\hline \multirow[t]{6}{*}{ Hexyl } & \multirow[t]{3}{*}{ Polypropylene tubes } & $37^{\circ} \mathrm{C}$ & $0.0102 \pm 0.0005$ \\
\hline & & $21^{\circ} \mathrm{C}( \pm 1)+$ light & $0.0097 \pm 0.0007$ \\
\hline & & $21^{\circ} \mathrm{C}( \pm 1)+$ dark & $0.0051 \pm 0.0080$ \\
\hline & \multirow[t]{3}{*}{ Borosilicate glass tubes } & $37^{\circ} \mathrm{C}$ & $0.0078 \pm 0.0018$ \\
\hline & & $21^{\circ} \mathrm{C}( \pm 1)+$ light & $0.0056 \pm 0.0022$ \\
\hline & & $21^{\circ} \mathrm{C}( \pm 1)+$ dark & $0.0024 \pm 0.0007$ \\
\hline \multirow[t]{6}{*}{ Heptyl } & \multirow[t]{3}{*}{ Polypropylene tubes } & $37^{\circ} \mathrm{C}$ & $0.0096 \pm 0.0007$ \\
\hline & & $21^{\circ} \mathrm{C}( \pm 1)+$ light & $0.0095 \pm 0.0008$ \\
\hline & & $21^{\circ} \mathrm{C}( \pm 1)+$ dark & $0.0045 \pm 0.0010$ \\
\hline & \multirow[t]{3}{*}{ Borosilicate glass tubes } & $37^{\circ} \mathrm{C}$ & $0.0076 \pm 0.0032$ \\
\hline & & $21^{\circ} \mathrm{C}( \pm 1)+$ light & $0.0068 \pm 0.0021$ \\
\hline & & $21^{\circ} \mathrm{C}( \pm 1)+$ dark & $0.0023 \pm 0.0005$ \\
\hline \multirow[t]{6}{*}{ Octyl } & \multirow[t]{3}{*}{ Polypropylene tubes } & $37^{\circ} \mathrm{C}$ & $0.0092 \pm 0.0009$ \\
\hline & & $21^{\circ} \mathrm{C}( \pm 1)+$ light & $0.0089 \pm 0.0016$ \\
\hline & & $21^{\circ} \mathrm{C}( \pm 1)+$ dark & $0.0044 \pm 0.0008$ \\
\hline & \multirow[t]{3}{*}{ Borosilicate glass tubes } & $37^{\circ} \mathrm{C}$ & $0.0060 \pm 0.0024$ \\
\hline & & $21^{\circ} \mathrm{C}( \pm 1)+$ light & $0.0068 \pm 0.0024$ \\
\hline & & $21^{\circ} \mathrm{C}( \pm 1)+$ dark & $0.0021 \pm 0.0003$ \\
\hline \multirow[t]{6}{*}{ Nonyl } & \multirow[t]{3}{*}{ Polypropylene tubes } & $37^{\circ} \mathrm{C}$ & $0.0096 \pm 0.0007$ \\
\hline & & $21^{\circ} \mathrm{C}( \pm 1)+$ light & $0.0095 \pm 0.0006$ \\
\hline & & $21^{\circ} \mathrm{C}( \pm 1)+$ dark & $0.0042 \pm 0.0007$ \\
\hline & \multirow[t]{3}{*}{ Borosilicate glass tubes } & $37^{\circ} \mathrm{C}$ & $0.0058 \pm 0.0020$ \\
\hline & & $21^{\circ} \mathrm{C}( \pm 1)+$ light & $0.0053 \pm 0.0017$ \\
\hline & & $21^{\circ} \mathrm{C}( \pm 1)+$ dark & $0.0024 \pm 0.0006$ \\
\hline
\end{tabular}




\begin{tabular}{|c|c|c|c|}
\hline \multirow[t]{6}{*}{ Decyl } & \multirow[t]{3}{*}{ Polypropylene tubes } & $37^{\circ} \mathrm{C}$ & $0.0088 \pm 0.0007$ \\
\hline & & $21^{\circ} \mathrm{C}( \pm 1)+$ light & $0.0091 \pm 0.0012$ \\
\hline & & $21^{\circ} \mathrm{C}( \pm 1)+$ dark & $0.0041 \pm 0.0009$ \\
\hline & \multirow[t]{3}{*}{ Borosilicate glass tubes } & $37^{\circ} \mathrm{C}$ & $0.0059 \pm 0.0022$ \\
\hline & & $21^{\circ} \mathrm{C}( \pm 1)+$ light & $0.0056 \pm 0.0017$ \\
\hline & & $21^{\circ} \mathrm{C}( \pm 1)+$ dark & $0.0023 \pm 0.0008$ \\
\hline
\end{tabular}

Table 2 - MIC values of hexyl and heptyl ferrocenyl chalcone compounds and DMSO control against nonresistant laboratory-adapted bacteria.

\begin{tabular}{|c|c|c|c|c|c|}
\hline \multirow[t]{2}{*}{ Organism } & \multicolumn{2}{|c|}{$\begin{array}{l}\text { MIC values in } \\
\text { polypropylene tubes } \\
(\mathrm{mg} / \mathrm{ml})\end{array}$} & \multicolumn{2}{|c|}{$\begin{array}{l}\text { MIC values in borosilicate } \\
\text { glass tubes }(\mathrm{mg} / \mathrm{ml})\end{array}$} & \multirow{2}{*}{$\begin{array}{l}\text { MIC values of } \\
\text { DMSO }(\% \mathrm{v} / \mathrm{v}) \\
\text { DMSO }\end{array}$} \\
\hline & Hexyl & Heptyl & Hexyl & Heptyl & \\
\hline $\begin{array}{l}\text { S. "Manchester" } \\
\text { NCTC } 7372\end{array}$ & 0.250 & 0.250 & 0.250 & 0.250 & 12.50 \\
\hline $\begin{array}{l}\text { E. coli NCIMB } \\
9483\end{array}$ & 0.250 & 0.500 & 0.250 & 0.500 & 25.00 \\
\hline $\begin{array}{l}\text { S. aureus NCIMB } \\
8244\end{array}$ & 0.063 & 0.016 & 0.063 & 0.031 & 12.50 \\
\hline $\begin{array}{l}\text { E. faecalis NCTC } \\
12697\end{array}$ & 0.125 & 0.031 & 0.125 & 0.063 & 12.50 \\
\hline
\end{tabular}

\section{Figures}




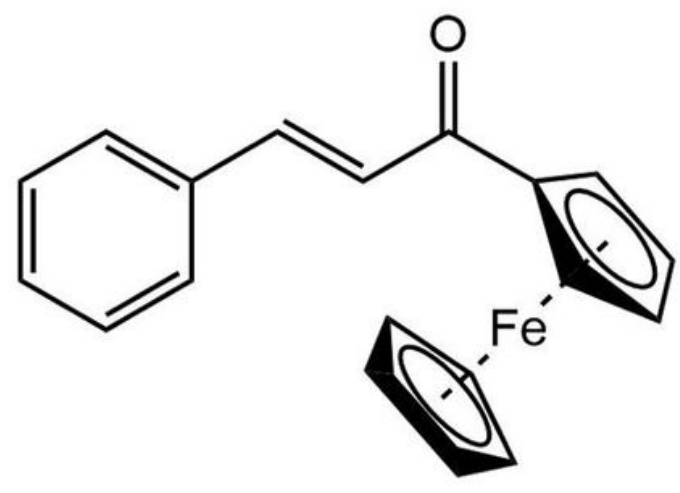

Type 1

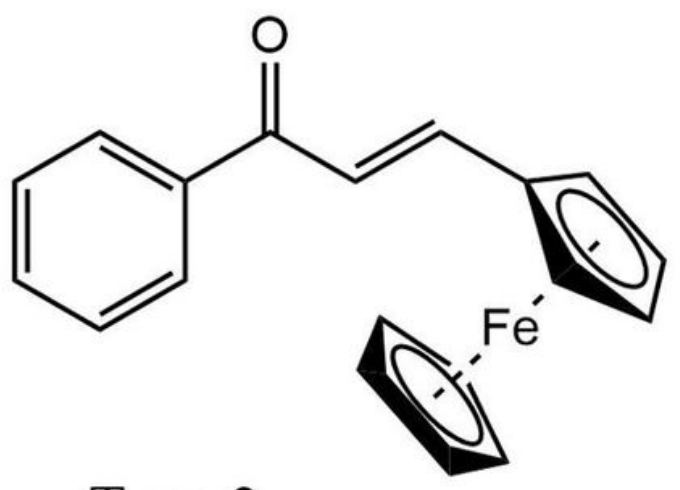

Type 2

Figure 1

General structure of Type 1 and Type 2 ferrocenyl chalcones [4],[10] 


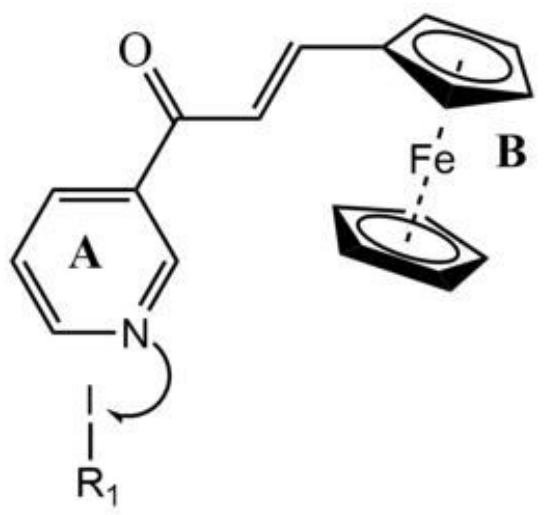

Ferrocenyl chalcone derivative

$\begin{array}{ll}\text { Attached R group } & \text { Name of final compound } \\ -\mathrm{CH}_{3} & \text { Methyl } \\ -\mathrm{C}_{2} \mathrm{H}_{5} & \text { Ethyl } \\ -\mathrm{C}_{3} \mathrm{H}_{7} & \text { Propyl } \\ -\mathrm{C}_{4} \mathrm{H}_{9} & \text { Butyl } \\ -\mathrm{C}_{5} \mathrm{H}_{11} & \text { Pentyl } \\ -\mathrm{C}_{6} \mathrm{H}_{13} & \text { Hexyl } \\ -\mathrm{C}_{7} \mathrm{H}_{15} & \text { Heptyl } \\ -\mathrm{C}_{8} \mathrm{H}_{17} & \text { Octyl } \\ -\mathrm{C}_{9} \mathrm{H}_{19} & \text { Nonyl } \\ -\mathrm{C}_{10} \mathrm{H}_{21} & \text { Decyl }\end{array}$

Figure 2

Structures of the ferrocenyl chalcones used in the Henry et al. study [10] 


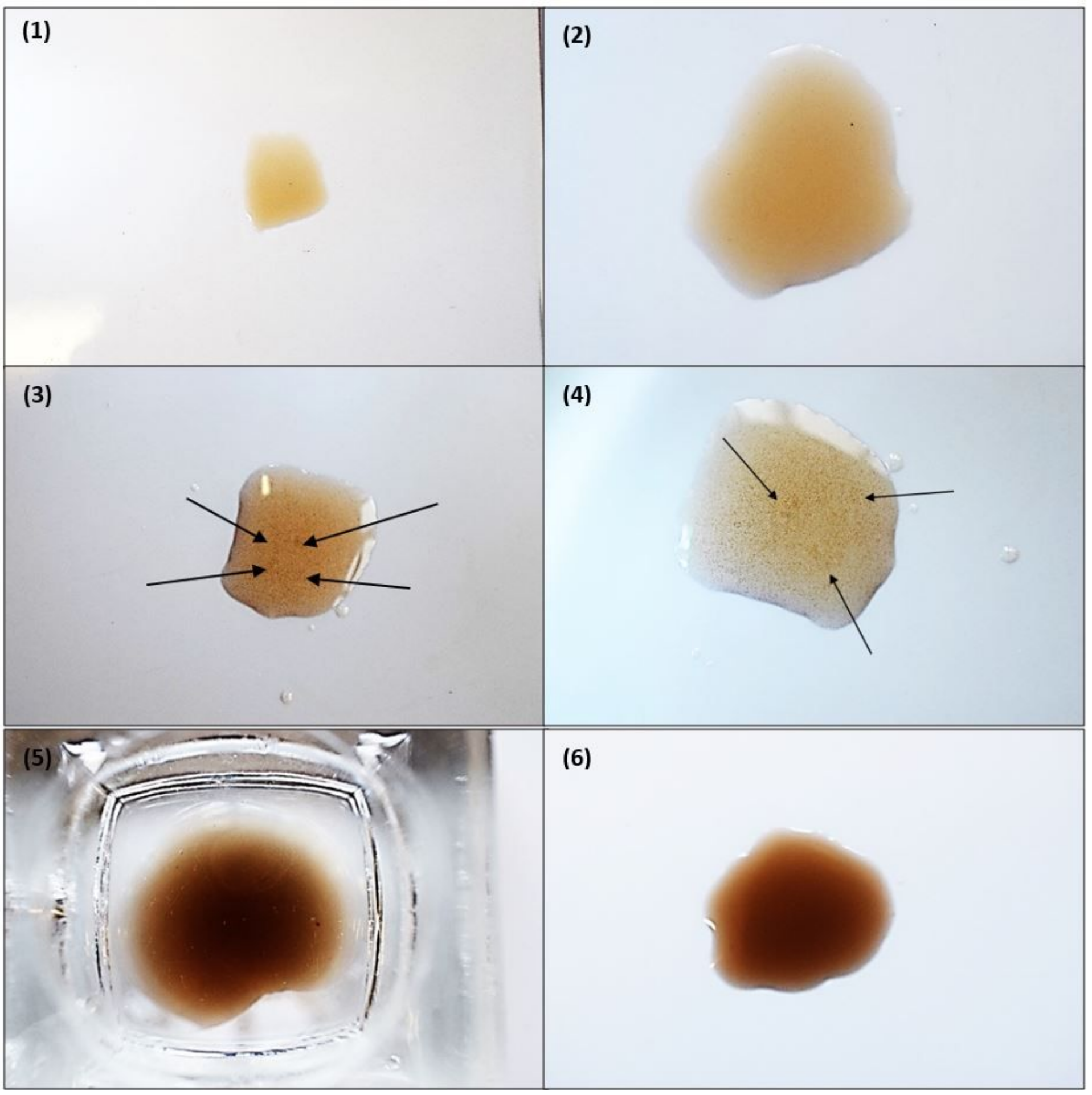

\section{Figure 3}

A 2-fold diluted nonyl ferrocenyl chalcone solution (1) with water as diluent post-incubation displaying no fine brown particles, (2) with water diluent after sonication and incubation displaying no fine brown particles, (3) with MHB diluent post-incubation showing aggregates of fine brown particles (black arrows), and (4) with MHB diluent after sonication and incubation showing aggregates of fine brown particles (black arrows). Stock nonyl ferrocenyl chalcone solution prepared (5) in a polypropylene tube with no observed fine brown particles and presented here in a glass well, and (6) in a borosilicate glass tube 

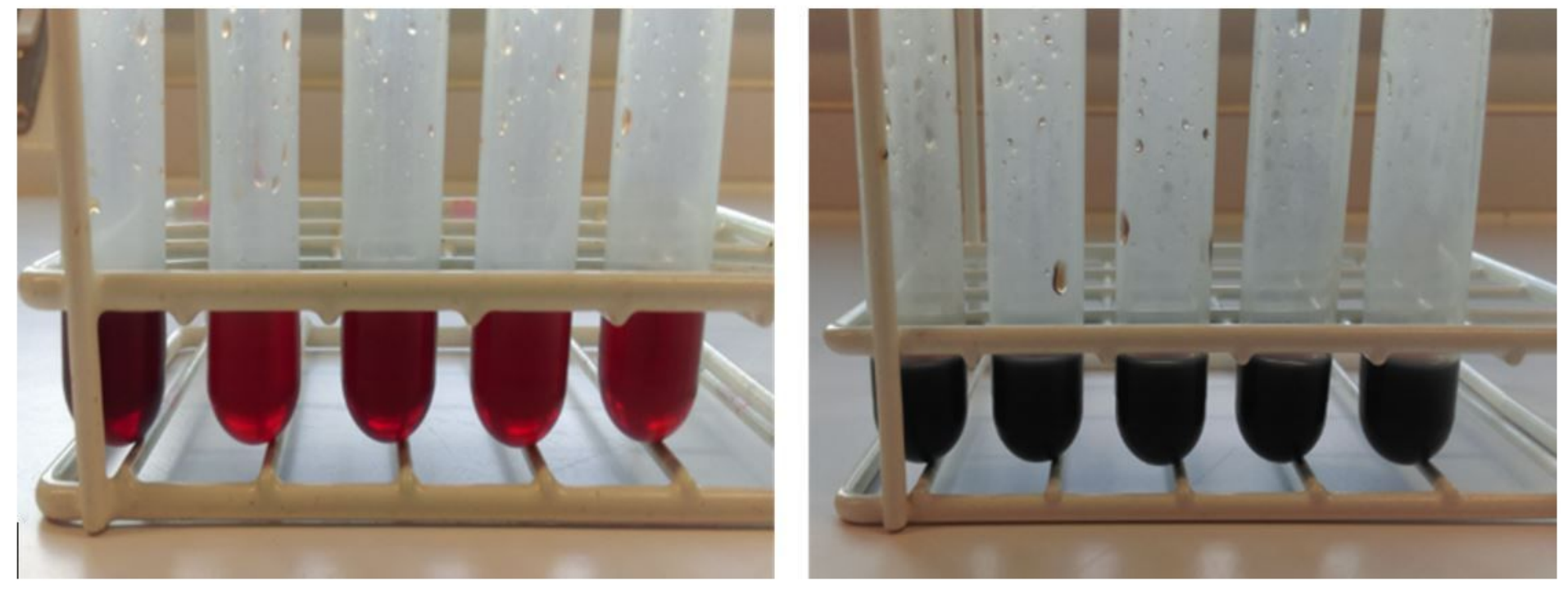

Figure 4

Colour change of the five ferrocenyl chalcones used at 0 minutes (left) and after five hours (right). The same colour change was observed in glass tubes. 